\title{
12
}

\section{The Brain Stress Systems II: The Mind Level of Brain Operations}

\begin{abstract}
In this chapter we continue our exploration of the neurobiology of functional somatic symptoms by considering the mind level of brain operations. Consciousness - the state of being aware, especially (for our purposes) of something within oneself-adds another dimension to the neurobiological systems that regulate body state. Among the objects of consciousness are feelings such as those pertaining to well-being and to dis-ease: pain, nausea, malaise, and fatigue. These feelings are mental representations of body state, a gestalt-like summary that integrates information from all levels of body regulation and that reflects the sum and substance of the individual as a whole. Feelings are consequently the end result of myriad interrelated processes: homeostatic information from the body itself (Chapters 6-10); spinal cord and implicit brain processes involved in both representing and regulating body state (Chapter 11); and - the subject of the present chapter-the
\end{abstract}

Electronic supplementary material The online version of this chapter (https://doi.org/10.1007/978-3-030-46184-3_12) contains supplementary material, which is available to authorized users. 
mind level of brain operations, including cognitive and attentional processes. These mind-level operations affect all of those other processes in a top-down manner and can alter feelings of body state in powerful ways that incline the child either toward health and well-being or toward ill health and dis-ease.

\section{Perceiving the Body: The Role of Feelings}

Consciousness refers to our state of being aware-especially (for our purposes) of something within oneself; it adds another dimension to the neurobiological systems that regulate body state. Among the objects of consciousness are feelings. Following Antonio Damasio's terminology, we conceptualize feelings as mental representations of body states: the idea, thought, or perception of the body being in a certain way (Damasio 2003). Homeostatic feelings are the particular focus of our attention here. They are mental representations regarding the safety and stability of the body's internal state, such as temperature, pain, nausea, fatigue, itch, visceral distension, muscle ache, hunger, thirst, and 'air hunger' (Craig 2002; Pace-Schott et al. 2019). 'They translate the ongoing life state in the language of the mind' (Damasio 2003, p. 85). These feelings, together with thoughts, mental and sensory images, and other conscious mental phenomena, make up what we recognize as the 'stream of mind' (Damasio 2003, p. 197). Throughout this chapter we use the terms mental representations of body state, perceptions of body state, and feelings interchangeably. For reading materials about consciousness, see Online Supplement 12.1.

In the normal course of events, the neurophysiological processes that support feelings are ones that function in the background, with no conscious awareness. These processes involve the following structures: nociceptors, thermoreceptors, osmoreceptors, and metaboreceptors; afferent nerve fibres that carry their signals; brain regions that map body state at different levels of processing; and brain regions that check and make adjustments for any discrepancies between the brain's predictions regarding the upcoming needs of the body and the actual incoming 
information about body state. When feelings emerge, they flag, in effect, that a given situation is important in one way or another.

They signify physiological need (for example, hunger), tissue injury (for example, [acute] pain), optimal [well-regulated] function (for example, well-being), threats to the organism (for example, fear or anger) or specific social interactions (for example, compassion, gratitude or love). Feelings constitute a crucial component of the mechanisms of life regulation, from simple to complex. Their neural substrates can be found at all levels of the nervous system, from individual neurons to subcortical nuclei and cortical regions. (Damasio and Carvalho 2013, p. 143)

Damasio's systemic framework provides us with a way of thinking about feelings on different levels of complexity (see Damasio [2003]). On the simplest level, the feeling may be solely the perception of a certain body state (Damasio 2003, p. 89). Here, feelings function to 'amplify the impact of a given situation, enhance learning, and increase the probability that comparable situations can be anticipated' (Damasio 2001, p. 781). For example, when our child (including adolescent) patients experience symptoms related to hyperventilation, the feelings they experience and describe all reflect the conscious perception of the physiological changes in body state caused by hyperventilation. These homeostatic feelings may include one of more of the following: buzzing in the head; varying degrees of reduction in the level of consciousness, described as dizziness, lightheadedness, giddiness, or faintness; blurring of vision; dryness of the mouth; numbness and tingling of the hands, feet, and face; stiffness of the muscles; and tetany. As the children learn to attend to these changes in body state and, in turn, to recognize the changes as a product of hyperventilation, they can undertake measures - mind-body interventions learnt as part of their treatment process - to control their dysregulated breathing, to change their physiological state, and to rid themselves of the particular homeostatic feeling (see Chapter 14).

On the next level, 'a feeling is the perception of a certain state of the body along with the perception of a certain mode of thinking and of thoughts with certain themes' (Damasio 2003, p. 86). Here, mental 
representations of body state are modulated by other processes that occur on the mind level of operations - processes that occur as part of a person's stream of mind. Examples from athletics are helpful in this context. A person who runs daily might, at some point, feel (on the first level, as above) somewhat fatigued but might also recognize that she is running especially well on that particular day. This additional layer will likely enable her to keep running and to actually feel less fatigued than she would on a 'standard' day of running. Going one step further, it has been shown that athletes have greater endurance when they are timing their efforts against a clock that has been calibrated to run slowly, creating the false impression that they have not been exercising as long as they actually have. Even intentional, known distractions or deceptions have an impact. Athletes are able to modify their feelings of fatigue by distracting themselves with music or by using a mirror to observe the non-fatigued arm when working with the opposite arm (see Noakes [2012] for review). Evie-the 15-year-old girl presenting with precordial catch syndrome and non-epileptic seizures (NES) whom we met in Chapter 9-described how her feelings of extreme pain were always accompanied by thoughts with certain themes.

When Evie experienced the bubble feeling of exploding pain in her chest, she would experience a negative mode of thinking and thoughts with negative themes: 'I can't stand this; I want to die; I hate myself; who invented this stupid thing; of all people I got this; I want to kill myself.' The pain and thoughts combined would trigger an NES. When the NES was over, the negative feelings remained. It would take some hours before the feelings of being overwhelmed and suicidal actually ebbed. [See Chapter 2 for history of Evie's presentation.]

On the final level, feelings can be generated by the brain itself - what Damasio calls the as-if-loop mechanisms. In this scenario, the brain can create mental representations of body state that do not correspond to the current reality of the body. This capacity enables us to feel empathy with others, to feel hope for the future, to shift our mind into 'wellness-thinking', and to use the felt experience of an anticipated future event to help optimize decision making (see vignette of Evie, 
below). Nevertheless, this same capacity to simulate feelings can contribute to feelings of pain when no injury exists, feelings of fatigue when exertion has been minimal, and feelings of nausea unconnected to current experience. The simulation of feelings can also shift one's mind into 'illness thinking' or generate felt fears or concerns about the future that impair or distort decision making.

In the following vignette, we see how a child used an as-if-loop mechanism to disrupt an emerging body state top-down.

Together with her therapists (the first author $[\mathrm{KK}]$ and a psychologist), Evie sequenced the temporal order of sensations: hot inside/cold outside, followed by tingling in the left arm, blurred vision, and perceived shortness of breath, along with burning in the throat and lump in throat, culminating in the pain bubble 'exploding' in her chest (precordial catch pain). Evie then practiced the implementation of a visualization-which invoked pleasant feelings via the as-if-loop mechanism — and was able, with time, to avert the tension pattern that progressed within her mediastinum and that culminated in the bubble feeling of exploding pain in her chest.

Cognitive processes appear to have a profound impact on body state in and of themselves. Anticipation of pain activates the amygdalae (part of the brain stress systems) (Strigo et al. 2010). Negative appraisals of a situation can activate the autonomic system top-down (Gianaros and Wager 2015). Catastrophizing activates posterior regions of the brain stress systems (Lee et al. 2018). In patients with chronic/complex pain, catastrophizing and attention to pain increase activation in the insulae (also part of the brain stress systems) (Kim et al. 2015). And in the case of patients who persistently worry about body symptoms that resemble, and are misinterpreted as, known medical diseases, findings on functional MRI (fMRI) show that the brain stress systems are overactive and over-dominant, and over-connect with motor- and sensory-processing regions (Kim et al. 2019b).

What emerges from these examples and this three-tiered typology of feelings is a recognition that feelings, except at the lowest level involving direct perception of body state, are the product of dynamic interactions between physiological states, neural maps of physiological states, 
perceptions of physiological states, and wide-ranging cognitive processes. More concretely, the mind level of brain operations-how the child thinks about herself and her functional somatic symptoms, how she processes the stressful events in her life, how she is influenced by her own moods, and the role of previous experience and learning-has a potentially profound impact on the child's perceptions (feelings) of body state, on the body state itself, and even on her functional somatic symptoms. These interconnections among feeling, thinking, and functional somatic symptoms are the focus of the present chapter.

\section{The Influence of Conscious Processes on Functional Somatic Symptoms}

Within the field of developmental psychology, a child's ability to control her thoughts, feelings, and focus of attention using top-down cognitive processes falls under the umbrella term of self-regulation (Posner 2012). By now the reader is well aware that in this book we use the term self-regulation much more broadly to include both top-down and bottom-up processes. In Chapters 5-11, we have already seen that children with functional somatic symptoms show significant difficulties with self-regulation on the body level and on the implicit level of brain operations. In the following subsections we shall see that children with functional somatic symptoms also struggle with regulation on the mind level of brain operations and that these difficulties contribute to the children's perceptions (feelings) of body state. Although we discuss conscious processes using commonly used constructs, it is important to emphasize that many of the constructs are overlapping and interdependent, and that in clinical practice they are often impossible to separate and need to be managed in tandem.

\section{Attention}

'Everyone knows what attention is. It is the taking possession by the mind, in clear and vivid form, of one out of what seem several 
simultaneously possible objects or trains of thought' (James 1890, pp. 403-404). In this statement, William James was referring to what researchers now refer to as focal attention mediated by the executive attention network (Posner 2012), a network of brain regions that enable attention to be voluntarily directed and sustained on the mind level of brain operations, thereby bringing objects of consciousness into focus.

Attention plays a key role in determining how information about body state is processed. Focusing one's attention onto a body part increases blood flow in that part of the body (Darwin 1872). Bringing attention to body sensations biases the processing of selected stimuli, increases neural mapping at multiple levels, and is accompanied by changes the individual's perception (feelings) of body state (Bauer et al. 2014; Kim et al. 2019a). By filtering out competing sensory inputs, attention facilitates synchrony between groups of neurons; attentional processes can enhance sensory, motor, and cognitive processes by activating and strengthening synaptic linkages between neurons and by enhancing communication (connectivity) between brain regions. But attentional processes can also be maladaptive. In children with functional somatic symptoms, attention to symptoms can presumably enhance aberrant interoceptive, sensory, motor, and perceptual processes by activating and strengthening aberrant synaptic linkages between groups of neurons and by enhancing connectivity between brain regions involved in symptom production. These linkages will need to be weakened or deactivated if health and well-being are to be restored.

The important role of attention in worsening or maintaining functional somatic symptoms in children is well documented (Walker et al. 2006; Palermo et al. 2014). For example, functional neurological symptoms typically increase in severity with attention and decrease in severity or even disappear when the child is paying attention elsewhere (Faust and Soman 2012; Stone 2014). A similar pattern is typical in children who present with chronic pain or persisting fatigue. Very often the pain or fatigue is most evident when the child is attending to the symptom or when a parent or doctor is asking about it, and least evident when the child is engaged in, and attending to, an activity that she enjoys. In this context, once the diagnostic assessment has been completed, an 
explanation and diagnosis has been provided, and treatment has been initiated, ongoing attention to functional symptoms, rather than to the interventions that can make the symptoms better, is generally counterproductive. Such symptom-focused attention, whether by the child, parent, doctors, or self-help group, will have the effect of making the symptoms worse and potentially chronic.

Johnny was a 9-year-old boy with a three-year history of functional gut symptoms (abdominal pain, nausea, and diarrhoea), six-month history of whole-body jerking, and three-month history of episodes of chest pain during which Johnny felt he could not breathe, was dizzy and lightheaded, and had intermittent loss of vision. More recently, Johnny's pain had begun to migrate over his whole body, and he began to experience periods of arm and leg paralysis that lasted up to six hours. Despite Johnny's many visits to the family doctor, emergency department, and paediatrician, the doctors said that Johnny's physical examination was normal, that all his tests were normal, and that they could find nothing wrong. Johnny's parents were unable to accept the medical verdict because they had to manage Johnny's symptoms on a daily basis and knew that the symptoms were real and functionally impairing. Despite repeated physical examinations and tests, Johnny's parents became more and more worried that some serious medical condition had being missed. They paid Johnny's symptoms more and more attention; they asked about the symptoms many times a day; and when new symptoms appeared, they filmed them. Johnny also was worried about his symptoms. He did not tell his parents, but secretly he thought he had some terrible disease and was going to die. In this highly charged context, in which Johnny's symptoms received constant attention, the symptoms progressively worsened, and with increasing frequency Johnny used a wheelchair to move around at school.

Raymond was a 12-year-old boy with a long history of anxiety, beginning with severe separation anxiety at ten months of age. Two years ago, prior to admission to the Mind-Body Program, he started to experience transient, recurring functional somatic symptoms-joint pains, bilateral leg weakness, and losses of vision-all in the context of significant family stress related to parental illness. Six months prior to admission, 
he began to experience stronger, more persistent pain in his right knee. Because weight bearing caused Raymond pain, he avoided using his right leg whenever possible, keeping it still and also elevating it if possible. With time, Raymond developed chronic regional pain syndrome (CRPS) with secondary complications related to his avoidance of weight bearing on his right leg (loss of bone density in the right femur and decreased range of movement in the ankle joint, documented under general anaesthetic). Raymond was admitted into the Mind-Body Program to treat his CRPS and transient losses of vision. Raymond now also reported severe pain in his right foot, and he refused to put any weight on it. His anticipatory anxiety was so great that he would begin to yell and scream-and to hide from the physiotherapist-as the time of his physiotherapy session approached. During some of these episodes, he also reported a loss of vision: 'I can't see, I can't see.'

Despite all the above, Raymond enjoyed therapy sessions with his psychologist, especially those in which his therapist used hypnosis. In one hypnosis session the role of attention in amplifying Raymond's pain was made especially clear. After inducing a trance state, the therapist suggested that Raymond relax his body and let the tension go. Raymond's body became progressively more relaxed. When the therapist focused Raymond's attention to the right foot—by making a direct suggestion pertaining to the foot-Raymond became agitated, his body made small jerky movements, and he began to pick at his arms, legs, and face. After coming out of the trance state, Raymond noted that as soon as the therapist had shifted his attention to his foot, the pain in the leg had spiked.

\section{Hypervigilance to Threat, Negative Appraisal Processes, and Rumination}

The appraisal and coping framework was put forward by Lazarus and his colleagues in a number of landmark publications (Lazarus 1966; Lazarus and Folkman 1984). Appraisal processes ascribe meaning, including threat-related meaning, to events in the external world, to body sensations, and to other images in the stream of mind-thoughts, memories, narratives, or other images - that arise at the mind level of brain operations. Primary appraisal processes include magnification and 
rumination, and secondary appraisal processes include helplessness. In this framework, these two types of processes work together to determine whether-and, if so, which—coping strategies will be employed.

Since the introduction of the appraisal and coping framework in the 1960s, rapid advances have been made in understanding the neurobiology of appraisal processes. We now know that the medial prefrontal cortex (part of the brain stress systems) is involved both in appraising information and in activating the efferent component of the autonomic system that fine-tunes body state on a second-by-second basis. What this means in practice is that when a child ascribes a threat-related meaning to an event, body sensation, or mental image, the prefrontal cortex will automatically switch on the autonomic nervous system component of the stress system and activate the body to prepare it for the upcoming threat (see Gianaros and Wager [2015] for review). These couplings between appraisals and body states establish brain-body pathways linking psychological stress - the threat-related meaning ascribed to events and mental images — and body state. In this way, the cognitive act of appraising events and mental images as threatening will activate the brain-body stress systems and, in particular children, will contribute to the generation and maintenance of functional somatic symptoms. By the same token, altering the cognitive appraisal of events and mental images - so that they are no longer seen as threatening-will help to decrease and even extinguish functional somatic symptoms. Accordingly, maladaptive appraisal processes are an important target of therapeutic intervention.

An ample literature suggests that maladaptive patterns of stress appraisal by children or their parents are associated with less healthy coping strategies, the development of functional somatic symptoms, and greater functional disability (Williams et al. 2011; Walker et al. 2007; Wallrath et al. 2019). Likewise, the importance of maladaptive appraisal processes and rumination has also been documented in adult patients with NES (see summary in Testa et al. [2012]), in patients with chronic fatigue (see summary in Meeus et al. [2010]), and chronic pain conditions more generally (see Jackson et al. [2014] and Kim et al. [2015]). In patients with chronic pain, threat appraisals have positive 
overall correlations with pain intensity, impairment, affective distress, and passive coping, and such appraisals are negatively related to active coping (Jackson et al. 2014).

In the vignettes below, we highlight how these processes emerge in daily clinical practice. For more about meaning making as part of family or individual narratives about the meaning of certain events (whether single events or longer series of interconnected events, as in a family history or one's life story), see Online Supplement 12.1.

Hypervigilance to threat. Zia was a 13-year-old girl who presented with headaches, dizziness, recurrent fainting and collapse events, and weakness in her legs. Zia lived with her father and her three brothers. During Zia's preschool years, all the children had been exposed to substantial abuse and neglect. Each morning, Zia and her siblings made the ten-minute walk from the family home to the bus station to catch a bus to school. Before leaving the house each morning, Zia's father would warn his children to stick together and keep an eye out for one another. Upon walking out the front door of their home, Zia was immediately on high alert for any unusual or sudden noises or dangerous-looking strangers. At the bus station and on the bus itself, she would scan the street and the bus for any person who appeared dangerous or threatening, for anyone who could hurt or threaten her brothers, and for anyone who looked like a potential child molester. If a stranger looked dangerous, Zia would move her brothers away. On the way home from school, Zia remained on high alert. Once home, Zia would collapse in a heap on the couch, with an intense headache and feeling exhausted from the day.

Negative appraisals. Anne-Marie was a 10-year-old girl with a 13-month history of pain and weakness in her legs; she was confined to a wheelchair. Through her various illness behaviours, Anne-Marie engaged her mother and siblings in fetching and carrying for her. She had previously experienced domestic violence, including her father's verbal abuse and his threats to kill the family. Her mother and siblings eventually fled the family home to obtain refuge (and safety) from the father. In the Mind-Body Program, because standing on her legs caused her pain, Anne-Marie appraised land-based physiotherapy as threatening and unacceptable. She therefore blankly refused to engage in physiotherapy or any activity that 
included weight bearing on land. If pushed to do so, she would become increasingly anxious and would go into shutdown as a defence mechanism, a state in which no one could reach her. By contrast, Anne-Marie appraised water-based physiotherapy as safe; in water-based sessions she swam around like a fish, with no pain in her legs.

Rumination. Owen was an 11-year-old boy with functional neurological disorder-shaking in the arms and legs, and weakness and loss of coordination in the legs-who presented in the context of severe bullying at school. When walking, Owen made his way slowly in a bizarre, laborious, wide-based, shaky gait. On admission to the Mind-Body Program, he was particularly worried about going to the hospital school. The night before his first attendance, he ruminated about the hospital school throughout the night-'I don't want to go', 'I don't know anyone', 'It's a new place', 'It will be awful' - and was unable to sleep. When he arrived at the hospital school, he kept thinking about how awful it was to be there, and he spent considerable time texting his ruminations to his parents. The never-ending stream of rumination meant that Owen never actually stopped to notice that hospital school was not as awful as he expected. Managing his ruminations became a key part of the psychological component of his treatment intervention. By the end of the admission, Owen loved the hospital school and was very sad to leave.

Rumination. Raymond-the boy with CRPS whom we met earlier in the chapter-was not the only anxious member in the family. Raymond's mother was also a worrier. In a discharge-planning meeting, when the discussion turned to Raymond's return to school, the mother voiced all the worries that had been running through her mind with regard to Raymond's return to school: 'He's not physically or mentally ready to go back to school'; 'If his foot gets knocked, he will not be able to manage his distress'; 'He might get teased'; 'He might be seen as different'; 'The teachers and other students might see him as a student with special needs'; 'He might feel uncomfortable in a role where he was dependent on others'; and so on. Raymond's father, who was well familiar with his wife's anxious thoughts, referred to this process as 'building bridges', a process by which his wife expended much mental energy rehearsing all possible future scenarios-all possible bridges that she might have to cross. 


\section{Catastrophizing}

A related construct is that of catastrophizing. To catastrophize means 'to imagine the worst possible outcome of an action or event: to think about a situation or event as being a catastrophe or having a potentially catastrophic outcome' (Merriam-Webster's Online Dictionary). When catastrophizing, the individual engages in a process that involves active rumination and excessive magnification of negative cognitions and feelings - typically feelings of helplessness, often coupled with feelings of pain, fatigue, nausea, and so on-with regard to an approaching situation. In this way, the act of catastrophizing invokes the human ability to create mental images that symbolize potential future outcomes. Even though the mental images generated in catastrophizing are imaginary - they are generated by the brain — they engage the attentional and appraisal processes described earlier in this chapter. In addition, when articulated aloud, catastrophic thoughts help maintain the unhealthy dynamics by which parental attention and responsiveness to the child's symptoms are maintained (Williams et al. 2011) or by which a parent's own catastrophizing contributes to the maintenance of the child's symptoms (Palermo et al. 2014; Frerker et al. 2016). Catastrophizing is another example of an adaptive process - the capacity to anticipate and plan responses in order to facilitate survival—gone awry.

While catastrophizing about pain has received most attention in the literature-showing a clear impact of catastrophizing on the severity of symptoms and illness-catastrophizing is common across functional somatic presentations. Imaging studies of catastrophizing suggest that it contributes to symptom persistence and amplification because it activates the brain stress systems and increases connectivity between the brain stress systems and sensory-processing regions, which is a pattern that occurs across functional presentations (see Chapter 11). For references see Online Supplement 12.1.

Morgan, the adolescent whom we met in Chapter 10, was a 15-year-old girl with a four-week history of hemiparesis and sensory loss on the left side of her face and body, a three-year history of chronic headache, fatigue, and intermittent NES, and a nine-year history of functional gut 
symptoms (recurring abdominal pain accompanied by nausea, difficulties eating, and irregular bowel function). Morgan was a catastrophizer. With her therapist, Morgan tracked her thoughts about an upcoming test: 'If I don't study now, I will fail my English test; if I fail my English test, this will mean that I keep going badly in English until I get a bad mark in the HSC [Australian examination for university admission]; if I get a bad mark in the HSC, then I won't get into university; without skills, I will end up being a checkout chick; but because I am not good with numbers, they would sack me; and so I will end up homeless, depressed, on drugs, and living on the street.'

\section{Feelings and Thoughts in Regulating Body State}

\section{Negative Feelings, Anxiety, and Depression}

Negative feelings - fear, anger, and sadness - as well as anxiety and depression, also affect the perception (feelings) of body state and the manner in which children with functional somatic symptoms perceive and manage their symptoms (see second-level feelings described within Damasio's framework, above). Very often it is not possible to effectively treat the somatic symptoms unless the comorbid negative feelings, anxiety, or depression are addressed. Readers interested in this area of research may like to look up the references provided in Online Supplement 12.1. In the vignettes below, we provide some examples of how negative feelings crop up in clinical practice with children.

Hopelessness. Morgan, the catastrophizing 15-year-old girl with functional neurological disorder whom we met above, felt hopeless about her situation and did not think that anything could change for her. Her stream of mind included a constant stream of rumination about her helplessness and the futility of the medical profession: 'The doctors can't help'; 'Nobody knows what's wrong with me'; 'You don't believe that there's anything wrong'; 'Yet another doctor has said they can't fix me'. Despite repeated conversations about Morgan's diagnosis and prognosis with her therapist, she kept returning to these thoughts. All attempts to use cognitive strategies to modify this stream of rumination made little difference. 
It was only after Morgan had been on a therapeutic dose of an antidepressant (a selective serotonin reuptake inhibitor [SSRI]) for some time that these thoughts started to decrease in intensity. Whenever Morgan became stressed and her mood dipped, however-because of a setback in her progress or because of social or exam stress at school—her hopeless thoughts would return, and she had to work hard to manage the thoughts so that they did not overwhelm her.

Fear. Raymond, the 12-year-old boy with CRPS whom we met earlier in the chapter, had an intense fear of movement, weight bearing, and bumping his leg. In the initial stages of Raymond's admission, this fear blocked all treatment efforts. When Raymond woke up in the morning, he was conscious of his fear of the physiotherapy that was to happen that day. Lying in bed he would begin to ruminate and catastrophize: 'I don't want to go to physio'; 'They're going to set unrealistic goals for me'; 'I'll never be able to reach them'; 'Everyone is going to be disappointed in me'; 'I'll never walk again'; 'I won't be able to make it home by Christmas; I'll be in hospital forever'. By the time the physiotherapist arrived, Raymond was in a state of panic characterized by an elevated heart rate, elevated respiratory rate, and raw fear that led him to hide under the sink in the bathroom while shaking in fear. If the physiotherapist tried to lure Raymond out from under the sink, he would begin a long period of loud, distressed screaming.

Anger. Taylor was a 15-year-old girl with a three-year history of anxiety and recurring diarrhoea and abdominal pain, a two-year history of dizziness and fainting, and a two-week history of NES that had begun after Taylor had been prescribed an SSRI for her anxiety by her referring doctor. Increased too quickly-and at doses that were too large- the SSRI had agitated Taylor and increased her physiological arousal. During her hospital admission, Taylor experienced prolonged NES, during which she shook and from which she could not be roused. In her work with her psychotherapist, Taylor identified that a feeling of anger preceded all her NES. Taylor was especially angry with her mother, who had high expectations for Taylor's performance at school and who pushed her ruthlessly and relentlessly to do well. Taylor came to recognize that any interaction with her mother or hospital staff that triggered intense anger-for example, being told that she had to go to the hospital school—triggered an NES. 


\section{Putting Unwanted Material Out of Mind}

Some children try to put unwanted negative thoughts, feelings, and memories out of mind. Different psychotherapy traditions have used different words for this phenomenon, including inhibition, suppression, and denial and avoidance of unwanted thoughts, feelings, and memories. A robust body of work now shows that putting unwanted negative thoughts, feelings, and memories out of mind is associated with increased physiological arousal and with increased activation of the brain stress systems. And when the unwanted material does come to mind, it can also be associated with very significant arousal. Further, a number of studies highlight that the cognitive process of putting unwanted negative material out of mind can contribute to functional somatic symptoms. For references see Online Supplement 12.1. Below we provide some vignettes of how putting unwanted material out of mind crops up in clinical practice with children.

Putting feelings into the box. Evie is the 15-year-old girl with precordial catch syndrome (sharp exploding pain in chest) and NES whom we met earlier in the chapter (see Chapter 2 for details of Evie's presentation). When asked about her mood during the family assessment interview, Evie said that she was 'fine'. Later it emerged that when Evie experienced the sharp exploding pain in her chest, she experienced suicidal ideation and wanted to kill herself. When asked why she had not mentioned this information, Evie said she had put the thoughts into her 'box'. When the feelings were in the box, she did not think about them, and they did not exist. In addition, Evie's relationship with her father-with whom she had been very close-had broken down 18 months before. But on the Early Life Stress Questionnaire (ELSQ), a checklist of 19 stress items, Evie had not ticked the section pertaining to family conflict. When asked why she had not included her conflicted relationship with her father on the questionnaire, Evie said that she no longer considered her father as part of her family and had therefore not ticked the questionnaire section. She had also put the conflict with her father in her 'box'.

Inhibition/suppression/deniallavoidance of unwanted thoughts, feelings, and memories. Victoria was a 17 -year-old girl who presented with intense 
fatigue, amnesia (e.g., lack of recognition of her parents and siblings), clouded thinking, violent episodes of trembling, and pain and weakness in the legs after falling down some stairs near the school playground. Victoria also suffered from symptoms of post-traumatic stress disorder in relation to a sexual assault by a sports coach two years previously, which she had recently disclosed to her youth group leader. Even when Victoria's amnesia and clouded thinking began to clear, she refused to discuss the assault with anyone (including the police). She told her therapist that she did not want to think about the assault and that she would continue to manage the memories by blocking them out of mind. Despite all of Victoria's efforts, the unwanted material emerged at night-in the form of nightmares - and during the day in the form of fear: fear that people were looking at her, fear of men, and fear of being touched in any way. Victoria's body was also permanently activated in a state of high arousal, which was reflected in an elevated respiratory rate (20-30 breaths per minute with a $\mathrm{pCO}_{2}$ of $23-29 \mathrm{~mm} \mathrm{Hg}$ ), a heart rate frequently in the range of $95-120$ beats per minute, nights that were punctuated by nightmares, and frequent panic attacks during the day and night, during which her heart rate, respiratory rate, and trembling reached their maximum levels.

\section{Expectations}

Perceptions (feelings) of body state are significantly modulated by expectations - by what the child anticipates/expects to happen. Sometimes the anticipated body state- of pain or nausea or fatigue or motor difficulties — can be triggered in the absence of any sensory input. This is an example of feelings from the third tier of Damasio's typology of feelings, where the brain creates mental representations of body state that do not correspond to the current reality of the body. In this way, negative expectations play an important role in triggering and maintaining functional somatic symptoms-in maintaining dis-ease-whereas positive expectations contribute to the process of getting well (Benedetti et al. 2013).

Positive expectations are part of the placebo effect. Research studies demonstrate that placebos work best when they activate already existent neural pathways - that is, pathways that have been primed by past 
experience. For example, when treating pain, the positive expectations that are activated as part of the placebo response reduce activity in pain-processing regions and brain stress systems, and increase activity in prefrontal cortical networks (which support positive expectations and the brain's dopamine reward systems) and subcortical regions (which support experience-dependent learning) (Wager and Atlas 2015; Dodd et al. 2017). Negative expectations or the nocebo response-an increase of symptoms following an intervention in the context of negative expectations (expectations that promote pain, distress, and dis-ease)-have the opposite effect; they decrease signalling in prefrontal cortical networks and the brain's dopamine reward system (Dodd et al. 2017).

Expectations of pain. During the family assessment, the power of Raymond's expectations of pain - the boy with CRPS whom we met earlier in the chapter-were enacted in the session. At one point in the interview, Raymond's sister, who was perched on a chair near the head of Raymond's bed, leaned her body slightly toward Raymond. As his sister leaned in, Raymond yelled, 'Ow, your hurting me, move away.' Raymond felt his anticipated pain even though his sister had not touched him.

Expectations of nausea and pain. Zack was a 17-year-old boy with a three-year history of nausea, feeling unwell following eating, recurrent abdominal pain, and difficulties maintaining his weight and nutritional status. Zack tried to eat as little as possible to avoid precipitating his symptoms. On admission to hospital Zack had strong expectations that feeds given via a nasogastric tube would trigger his symptoms. Zack's treating team knew that in the normal course of a day, the stomach secretes approximately $1500 \mathrm{ml}$ of fluid into the gastric lumen. In this context, the team examined the contribution of Zack's expectations by passing $1 \mathrm{ml}$ of fluid into his gastric lumen via the nasogastric tube. When $1 \mathrm{ml}$ of fluid was administered, Zack became white as a sheet; he began to sweat; and his heart rate and respiratory rate went up. He clutched his stomach, complained of excruciating pain, reached for his vomit bag, and begged for medication to relieve his pain. Following the 1 $\mathrm{ml}$ trial, Zack began to understand the power of his own mind. He realized that he could trigger his symptoms with just his mind. With the help of his psychologist, he worked on using his mind - via hypnosis, imagery, 
and other cognitive and body-regulation strategies-in more helpful ways, enabling him to manage his expectations and his symptoms.

In this chapter we have examined how cognitive processes - the mind level of brain operations - can be used in maladaptive ways and can contribute to the shaping and maintenance of functional somatic symptoms. All of the cognitive processes that we have discussed in this chapter are available to conscious awareness, and they make up what we recognize as the 'stream of mind' (Damasio 2003, p. 197). Because conscious processes are amenable to conscious manipulation, they also provide a therapeutic window for change. In Chapter 13, we look at principles of treatment that are built upon our systemic model, and in the chapters after that (14-16), we examine therapeutic interventions on different system levels: the body level, the mind level of brain operations, and the family and behavioural system levels.

\section{References}

Bauer, C. C., Diaz, J. L., Concha, L., \& Barrios, F. A. (2014). Sustained Attention to Spontaneous Thumb Sensations Activates Brain Somatosensory and Other Proprioceptive Areas. Brain and Cognition, 87, 86-96.

Benedetti, F., Thoen, W., Blanchard, C., Vighetti, S., \& Arduino, C. (2013).

Pain as a Reward: Changing the Meaning of Pain from Negative to Positive Co-activates Opioid and Cannabinoid Systems. Pain, 154, 361-367.

Craig, A. D. (2002). How Do You Feel? Interoception: The Sense of the Physiological Condition of the Body. Nature Reviews Neuroscience, 3, 655-666.

Damasio, A. (2001). Fundamental Feelings. Nature, 413, 781.

Damasio, A. (2003). Looking for Spinoza: Joy, Sorrow, and the Feeling Brain. Orlando, FL: Harcourt.

Damasio, A., \& Carvalho, G. B. (2013). The Nature of Feelings: Evolutionary and Neurobiological Origins. Nature Reviews Neuroscience, 14, 143-152.

Darwin, C. (1872). The Expression of the Emotions in Man and Animals. London: John Murray. 
Dodd, S., Dean, O. M., Vian, J., \& Berk, M. (2017). A Review of the Theoretical and Biological Understanding of the Nocebo and Placebo Phenomena. Clinical Therapeutics, 39, 469-476.

Faust, J., \& Soman, T. B. (2012). Psychogenic Movement Disorders in Children: Characteristics and Predictors of Outcome. Journal of Child Neurology, 27, 610-614.

Frerker, M., Hechler, T., Schmidt, P., \& Zernikow, B. (2016). Pain-Related Parental Behavior: Maternal and Paternal Responses to Chronic Pain of Their Child and Modifications Following Inpatient Interdisciplinary Pain Treatment. Schmerz, 30, 241-247.

Gianaros, P. J., \& Wager, T. D. (2015). Brain-Body Pathways Linking Psychological Stress and Physical Health. Current Directions in Psychological Science, 24, 313-321.

Jackson, T., Wang, Y., \& Fan, H. (2014). Associations Between Pain Appraisals and Pain Outcomes: Meta-analyses of Laboratory Pain and Chronic Pain Literatures. Journal of Pain, 15, 586-601.

James, W. (1890). The Principles of Psychology (Vol. 1). New York: Henry Holt $\&$ Co.

Kim, J., Loggia, M. L., Cahalan, C. M., Harris, R. E., Beissner, F. D. P. N., Garcia, R. G., et al. (2015). The Somatosensory Link in Fibromyalgia: Functional Connectivity of the Primary Somatosensory Cortex Is Altered by Sustained Pain and Is Associated with Clinical/Autonomic Dysfunction. Arthritis \& Rheumatology (Hoboken, NJ), 67, 1395-1405.

Kim, J., Mawla, I., Kong, J., Lee, J., Gerber, J., Ortiz, A., et al. (2019a). Somatotopically Specific Primary Somatosensory Connectivity to Salience and Default Mode Networks Encodes Clinical Pain. Pain, 160, 1594-1605. Kim, S. M., Hong, J. S., Min, K. J., \& Han, D. H. (2019b). Brain Functional Connectivity in Patients with Somatic Symptom Disorder. Psychosomatic Medicine, 81, 313-318.

Lazarus, R. S. (1966). Psychological Stress and the Coping Process. New York: McGraw-Hill.

Lazarus, R. S., \& Folkman, S. (1984). Stress, Appraisal, and Coping. New York: Springer.

Lee, J., Protsenko, E., Lazaridou, A., Franceschelli, O., Ellingsen, D. M., Mawla, I., et al. (2018). Encoding of Self-Referential Pain Catastrophizing in the Posterior Cingulate Cortex in Fibromyalgia. Arthritis \& Rheumatology (Hoboken, NJ), 70, 1308-1318.

Meeus, M., Nijs, J., Van Oosterwijck, J., Van Alsenoy, V., \& Truijen, S. (2010). Pain Physiology Education Improves Pain Beliefs in Patients with 
Chronic Fatigue Syndrome Compared with Pacing and Self-Management Education: A Double-Blind Randomized Controlled Trial. Archives of Physical Medicine and Rehabilitation, 91, 1153-1159.

Noakes, T. D. (2012). Fatigue Is a Brain-Derived Emotion That Regulates the Exercise Behavior to Ensure the Protection of Whole Body Homeostasis. Frontiers in Physiology, 3, 82.

Pace-Schott, E. F., Amole, M. C., Aue, T., Balconi, M., Bylsma, L. M., Critchley, H., et al. (2019). Physiological Feelings. Neuroscience and Biobehavioral Reviews, 103, 267-304.

Palermo, T. M., Valrie, C. R., \& Karlson, C. W. (2014). Family and Parent Influences on Pediatric Chronic Pain: A Developmental Perspective. American Psychologist, 69, 142-152.

Posner, M. I. (2012). Attention in a Social World. New York: Oxford University Press.

Stone, J. (2014). Functional Neurological Disorders: The Neurological Assessment as Treatment. Neurophysiologie Clinique, 44, 363-373.

Strigo, I. A., Simmons, A. N., Matthews, S. C., \& Craig, A. D. (2010). The Relationship Between Amygdala Activation and Passive Exposure Time to an Aversive Cue During a Continuous Performance Task. PLoS ONE, 5, e15093.

Testa, S. M., Krauss, G. L., Lesser, R. P., \& Brandt, J. (2012). Stressful Life Event Appraisal and Coping in Patients with Psychogenic Seizures and Those with Epilepsy. Seizure, 21, 282-287.

Wager, T. D., \& Atlas, L. Y. (2015). The Neuroscience of Placebo Effects: Connecting Context, Learning and Health. Nature Reviews Neuroscience, 16, 403-418.

Walker, L. S., Smith, C. A., Garber, J., \& Claar, R. L. (2007). Appraisal and Coping with Daily Stressors by Pediatric Patients with Chronic Abdominal Pain. Journal of Pediatric Psychology, 32, 206-216.

Walker, L. S., Williams, S. E., Smith, C. A., Garber, J., Van Slyke, D. A., \& Lipani, T. A. (2006). Parent Attention Versus Distraction: Impact on Symptom Complaints by Children With and Without Chronic Functional Abdominal Pain. Pain, 122, 43-52.

Wallrath, M. K., Rubel, J., Ohls, I., Demiralay, C., \& Hechler, T. (2019, November 29). Bottom-up or Top-down? The Role of Child and Parent Chronic Pain and Anxiety in the Context of Parental Catastrophizing and Solicitousness. European Journal of Pain (London, England) (Epub ahead of print).

Williams, S. E., Blount, R. L., \& Walker, L. S. (2011). Children's Pain Threat Appraisal and Catastrophizing Moderate the Impact of Parent 
Verbal Behavior on Children's Symptom Complaints. Journal of Pediatric Psychology, 36, 55-63.

Open Access This chapter is licensed under the terms of the Creative Commons Attribution-NonCommercial-NoDerivatives 4.0 International License (http://creativecommons.org/licenses/by-nc-nd/4.0/), which permits any noncommercial use, sharing, distribution and reproduction in any medium or format, as long as you give appropriate credit to the original author(s) and the source, provide a link to the Creative Commons license and indicate if you modified the licensed material. You do not have permission under this license to share adapted material derived from this chapter or parts of it.

The images or other third party material in this chapter are included in the chapter's Creative Commons license, unless indicated otherwise in a credit line to the material. If material is not included in the chapter's Creative Commons license and your intended use is not permitted by statutory regulation or exceeds the permitted use, you will need to obtain permission directly from the copyright holder. 